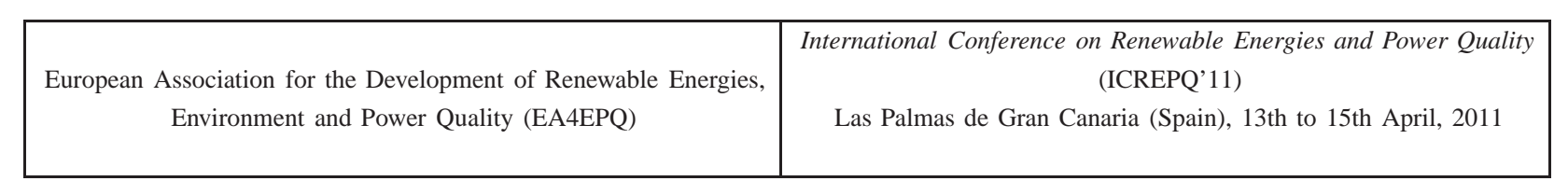

\title{
Small Wind Energy Systems. State of the Art and New Challenges
}

\author{
(Invited Paper) \\ M. Mañana \\ Department of Electrical and Energy Engineering \\ E.T.S.I.I.T. University of Cantabria \\ Avda. Los Castros s/n \\ 39005 Santander, Cantabria, Spain \\ Email: mananam@unican.es
}

\begin{abstract}
This paper is devoted to the analysis of small wind energy systems, including a review of the state of the art and new challenges.
\end{abstract}

\section{INTRODUCTION}

AWEA defines Small wind turbines (SWT) as having a generating capacity up to 100 kilowatts $(\mathrm{kW})(18 \mathrm{~m}$ or $60 \mathrm{ft}$ rotor diameter). Small Wind energy is a hot topic. A study of the American Wind Energy Association (AWEA) [1] shows that even considering the economic downturn, the U.S. market for small wind generators grew a $15 \%$ in 2009 with an added capacity of 20.3 MW. Fig. 1 summarizes the 2009 global sales considering both off-grid and on-grid applications. The aggregated data shows over 10,000 new generators and pushes the total installed capacity in the U.S. to more than 100 MW. It is important to underline that half of this installed capacity is concentrated in the last three years. This data is specially significative if we consider that the small wind industry started in the 30's. Manufacturers and other players related with this sector attribute the increase in the number and power of installed systems during the last period to three main facts:

- New and improved federal and state incentives.

- Optimistic private equity investors.

- Sustained consumer demand.

The USA government expanded the federal investment tax credit (ITC) for small wind turbines with several financial advantages, including tax credit of $30 \%$ of the total cost of a small wind system. At the same time, an additional investment of $\$ 80$ millions of private equity was injected in manufacturing company in 2009 during the worst period of the economic recession.

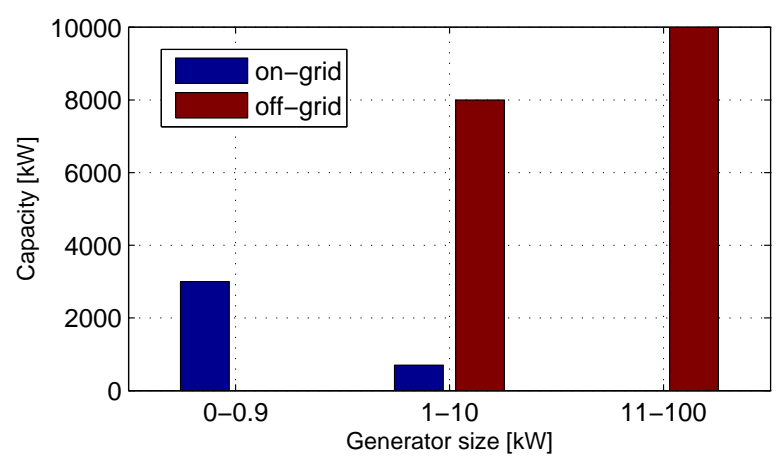

Figure 1. 2009 global sales of the U.S. small wind generator market [1].

Spain can be considered a reference model regarding wind energy generation. However, the total installed power of small wind generator is below $7 \mathrm{MW}$. It is expected that the installed power will increase in the nearest future with the development of the smart grids and the distributed generation paradigm.

TABLE I

Comparative OF SALES IN 2009 (ADAPTED From [1]).

\begin{tabular}{|c|c|c|}
\hline Spain Sales & U.S. Sales & Global sales \\
\hline 1 MW & $20.3 \mathrm{MW}$ & $242.5 \mathrm{MW}$ \\
\hline $100 \%$ growth over & $15 \%$ growth over & $10 \%$ growth over \\
\hline 2008 & 2008 & 2008 \\
\hline 500 units & 9,800 units & 21,000 units \\
\hline$\$ 4$ million in sales & $\$ 83$ million in sales & $\begin{array}{l}\$ 189 \text { million in } \\
\text { sales }\end{array}$ \\
\hline
\end{tabular}

At the moment there are more than 526 small wind turbines from 190 different manufacturers around the world [2]. The turbines can be included in two different 
sets:

- 426 Horizontal Axis Wind Turbines (HAWT)

- 100 Vertical Axis Wind Turbines (VAWT)

Acording to Fig. 1 it is expected that set-up facilities like the system it is presented in this paper will be neccessary in the next future in order to test the performance of the electrical machine and the power converter.

\section{Fundamentals of Wind EnERGy Conversion}

A wind energy conversion system extract kinetic energy from the air by means of blades that convert it into rotational energy that is delivered to a rotating electrical machine. The energy supplied by the electrical machine can be injected into the grid in a direct or indirect way by using a power converter. The maximum power that can be extracted from the wind is [3]

$$
P_{W_{\max }}=C_{P} A_{R} \frac{\rho}{2} v^{3}
$$

with,

$A_{R} \quad$ Effective are of the rotor.

$v \quad$ Wind speed.

$\rho \quad$ Air density.

$C_{P} \quad$ Betz's limit.

The eq. 1 was formulated by Betz a defines a value of $60 \%$ as the limit of the maximum energy/power than can be extracted from an airstream. From a practical point of view the real value of $C_{P}$ depends on the type of technology conversion and the tip speed ratio which is defined as

$$
\lambda=\frac{v_{u}}{v_{l}}
$$

with $v_{u}$ and $v_{l}$ been the peripheral an undisturbed wind velocity. Fig. 2 shows a comparison between the performance coefficient and the tip speed ratio for several types of turbines [4].

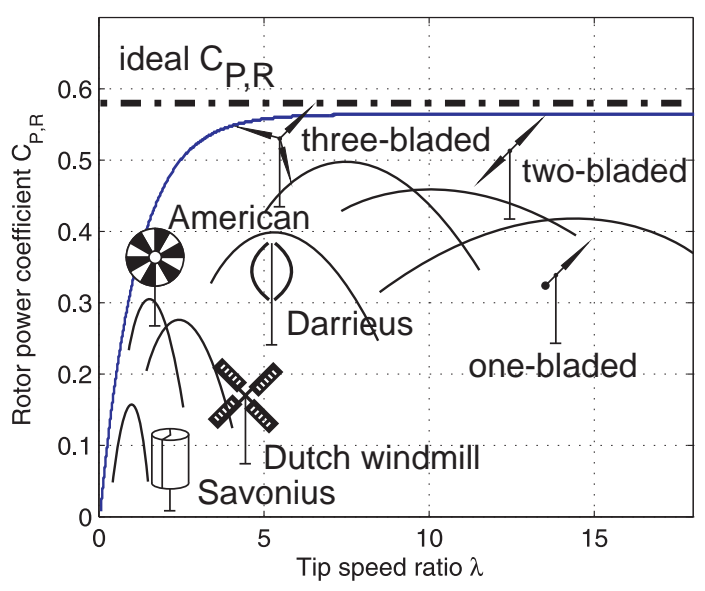

Figure 2. Performance coefficient vs tip speed ratio for several types of turbines.
In [5] is possible to find information about complementary devices that captures the windstream and guides it increasing the $C_{P}$ of the overall system.

\section{TECHNOLOGY REVIEW OF SMALL WIND GENERATORS}

The success of the small wind generation technology is related with the fact that it is open to people without any or small background on mechanical and/or electrical engineering. As an example, In 2008 William Kamkwamba [6] constructed a crude windmill armed with some old text books and an incredible determination as a probe that small wind generation is not rocket science. Fig. 3.a shows an image of the developed system. Fig. 3.b shows a state of art permanent magnet synchronous machine (PMSM) small wind generator manufactured by SonkyoGroup.

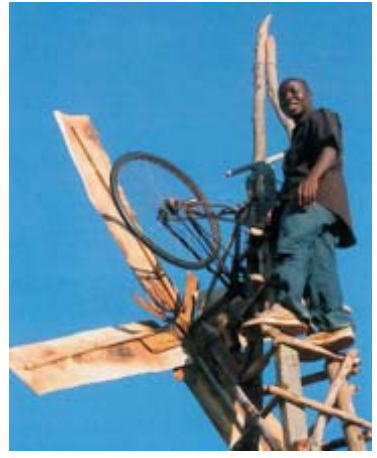

(a)

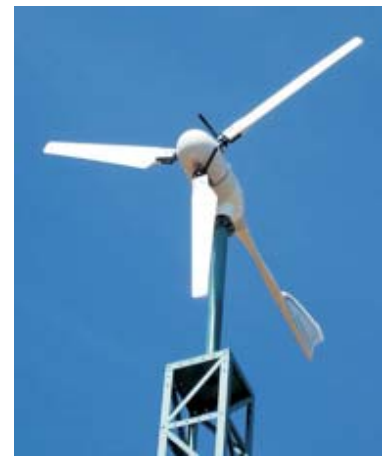

(b)
Figure 3. (a) small wind generator constructed by W. Kamkwamba; (b) Sonkyo state of the art PMSM small wind generator.

A small wind generation system includes not only the foundation and the rotor blades but also the electrical machine, the power converter and the auxiliary systems [7].

\section{A. Energy Converter System}

There are different technical solutions that can be used for energy conversion. These solutions can be classified according the type of electrical machine and/or power converter. Table II summarizes the basic solutions for converting mechanical energy to electrical energy using an asynchronous squirrel cage or short-circuit machine. In addition, Table III summarizes the energy conversion architectures for synchronous machines. With different approaches all the systems include an electrical machine and the power converter. Fig. 4 shows the basic architecture of a small wind generator.

1) Electrical Machine: From a general point of view, almost all the technological solutions are based on rotating field generators. Actually, asynchronous and synchronous generators with direct grid coupling or full or partial power converter are usually implemented. 


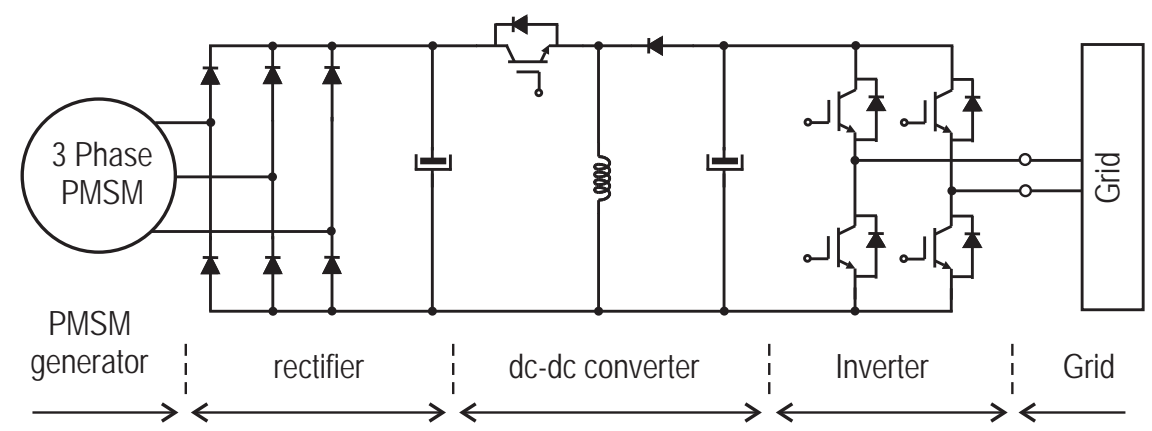

Figure 4. Basic equivalent circuit of the conversion system based on a three-phase PMSM.

2) Power Converter: The power converter works like an interface between the electrical machine and the grid. It provides support for maximum power tracking and enables grid integration by tracking grid voltage and frequency. In addition, the power converter also provides control over the reactive power and ride-through capabilities.

TABLE II

CONVERSION SYSTEMS BASED ON ASYNCHRONOUS SHORT-CIRCUIT AND SLING ROTOR MACHINES.
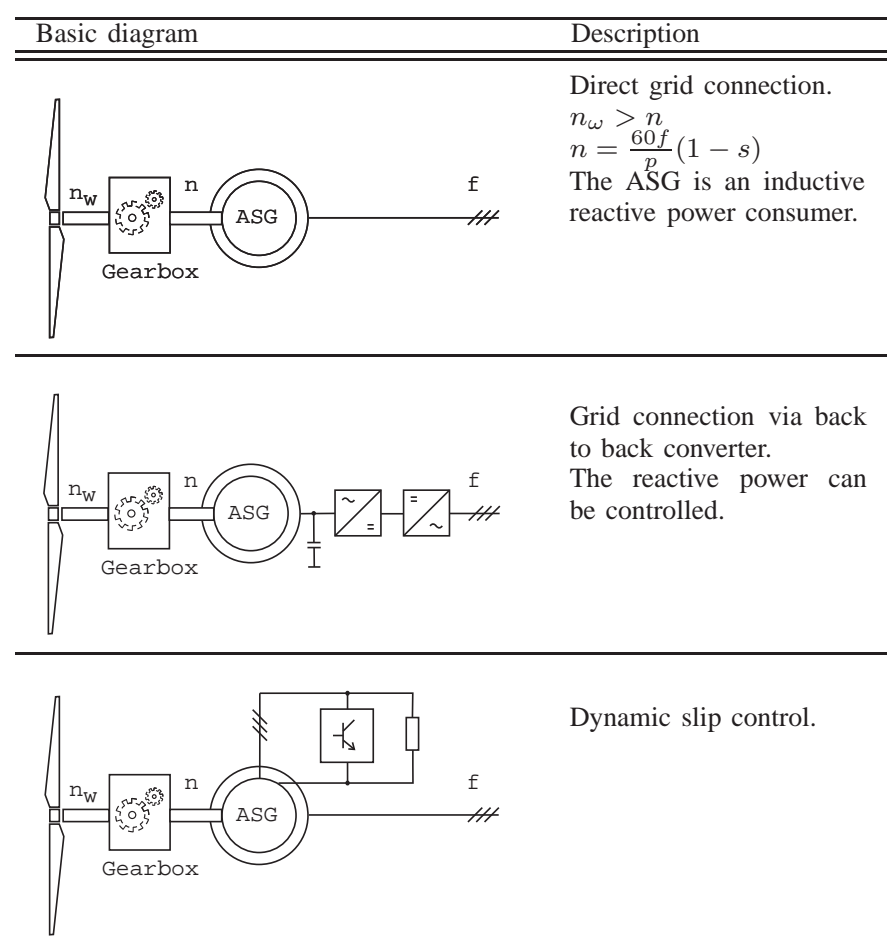

Dynamic slip control.

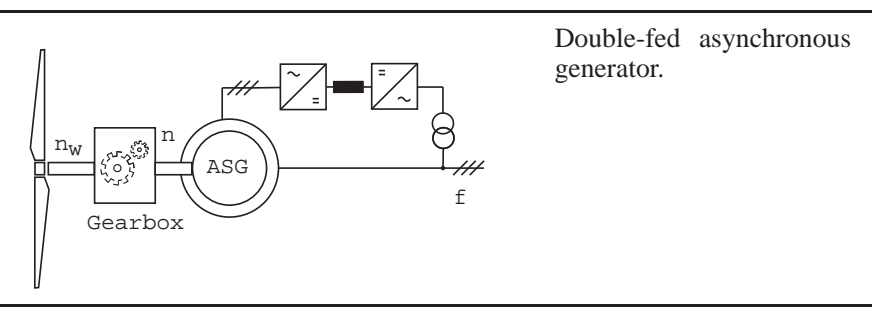

TABLE III

CONVERSION SYSTEMS BASED ON SYNCHRONOUS MACHINES.

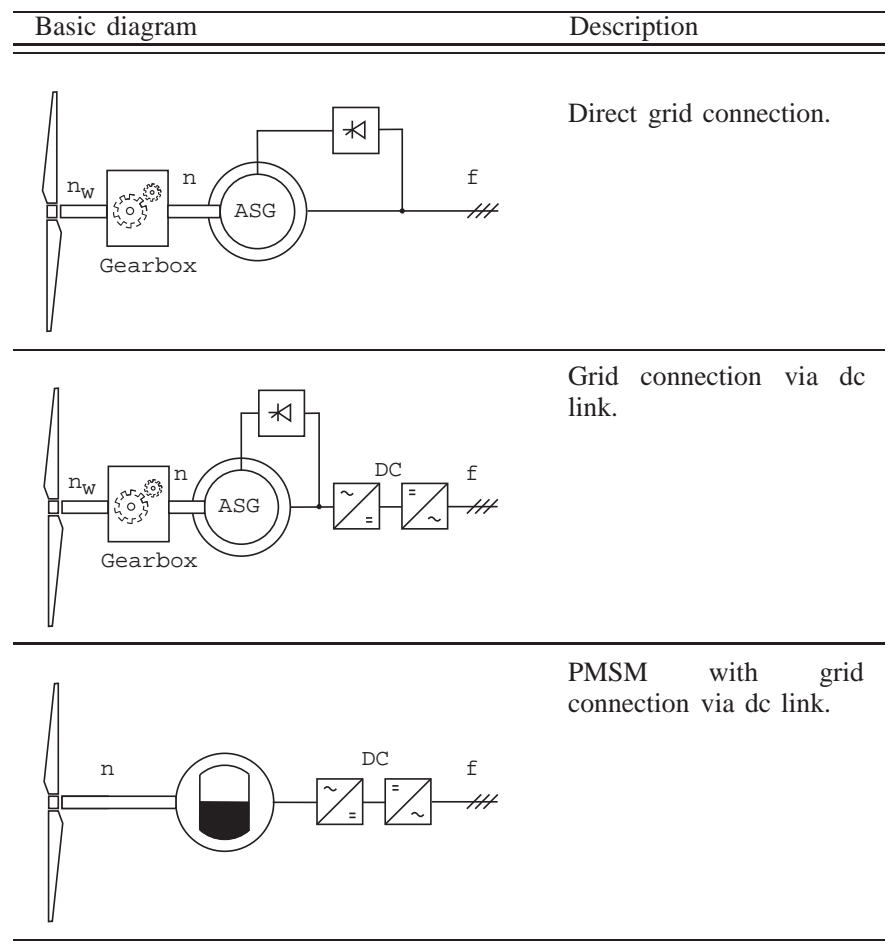

\section{ENVIRONMENTAL IMPACT}

One of the advantages of small wind generators is their limited environmental impact that only affects the immediate surroundings. The most important effects of this technology are:

- Noise emission.

- Shadow effects or potential interference with radio and/or tv signals.

- Power quality problems.

- Possible effects on animal life.

- Visual impact.

\section{CONCLUSIONS}

The small wind generation market has experienced a significative growth during the last decade and it is 
expected that it will be an important player in distributed generation in the next future. There is a competitive race between manufacturers around the world because there are more and more consumers demanding this technology. The development of this generation technology needs a stable regulatory framework and government support. From an energy conversion point of view, the PMSM is the electrical machine most widely used together with the full power converter.

\section{References}

[1] "Awea small wind turbine global market study," American Wind Energy Association (AWEA), Tech. Rep., 2010.

[2] http://www.allsmallwindturbines.com/. (last accessed 15th of november of 2010)

[3] S. Heier, Grid Integration of Wind Energy Conversion Systems. England: John Wiley and Sons Ltd., 2006.

[4] I. H. Abbott and A. E. von Doenhoff, Theory of Wing Sections: Including a Summary of Airfoil Data. New York: Dover Publications, 2006.

[5] http://www.twecs.org/ (last accessed 18th of february of 2011), Tornado Wind Energy Conversion System (TWECS), 2011.

[6] W. Kamkwamba and B. Mealer, The Boy Who Harnessed The Wind. London: HarperCollins, 2009.

[7] IEC61400-2, Wind turbines - Part 2: Design requirements for small wind turbines, 2006. 